\title{
FASCIST MODERNISM
}





\section{FASCIST}

MODERNISM

Aesthetics, Politics, and

the Avant-Garde

\section{ANDREW HEWITT}

Stanford University Press Stanford, California 
Stanford University Press

Stanford, California

(C) I 993 by the Board of Trustees of the

Leland Stanford Junior University

Printed in the United States of America

CIP data are at the end of the book

Stanford University Press publications are distributed exclusively by Stanford University Press within the United States, Canada, Mexico, and Central America; they are distributed exclusively by Cambridge University Press throughout the rest of the world. 
For Tony

- and the boys! 
